UCRL-JC-119216

PREPRINT

\title{
Magnetic X-Ray Circular Dichroism in Nickel-Gold Multilayers
}

\author{
A. F. Jankowski \\ G. D. Waddill \\ J. G. Tobin
}

This paper was prepared for submittal to the Fall Meeting of the Materials Research Society Boston, Massachusetts

November 28-December 2, 1994

November 11, 1994

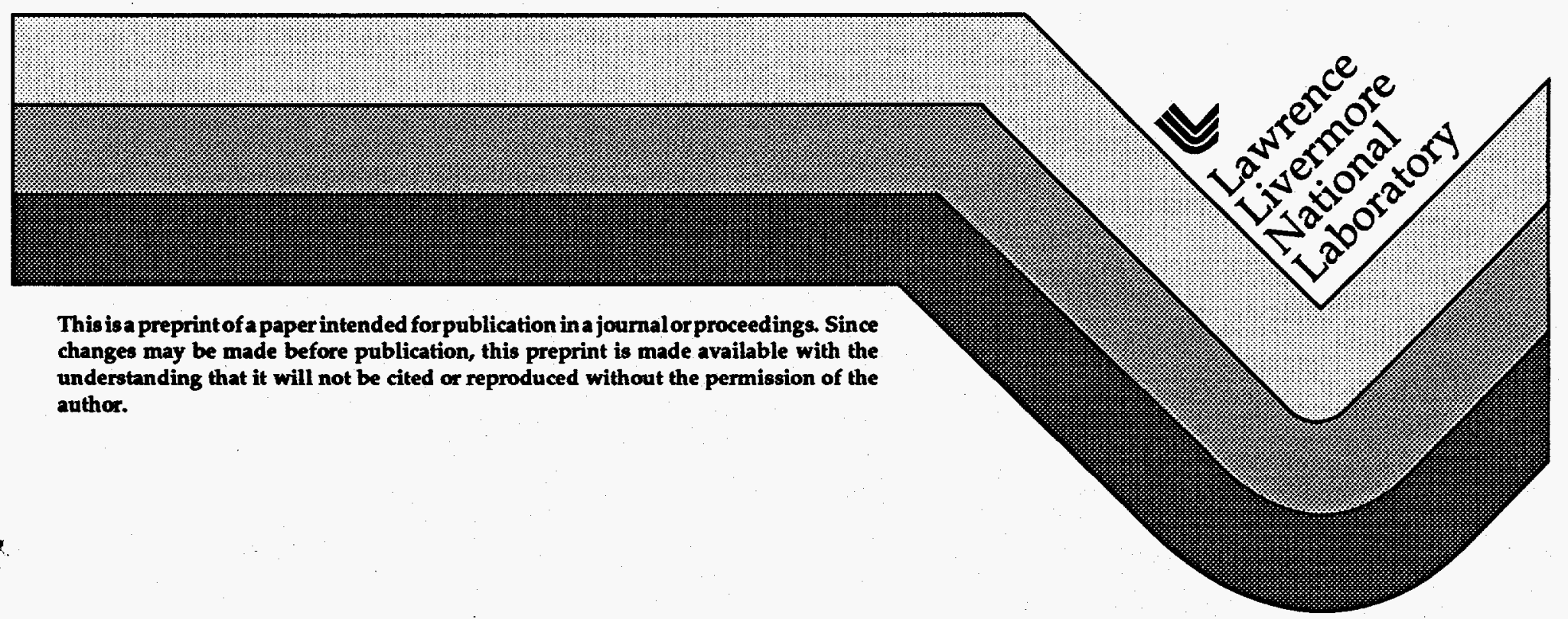





\section{DISCLAIMER}

Portions of this document may be illegible in electronic image products. Images are produced from the best available original document. 


\title{
MAGNETIC X-RAY CIRCULAR DICHROISM IN \\ NICKEL-GOLD MULTILAYERS
}

\author{
A.F. JANKOWSKI*, G.D. WADDILL**, and J.G. TOBIN* \\ *Lawrence Livermore National Laboratory, Livermore, CA 94551-9900 U.S.A. \\ **University of Missouri, Physics Department, Rolla, MO 65401-0249 U.S.A.
}

\begin{abstract}
Magnetic circular dichroism in $\mathrm{x}$-ray absorption is used to investigate the in-plane, remnant magnetization of well-characterized $\mathrm{Ni}_{0.48} / \mathrm{Au}_{0.52}$ multilayers. Large superlattice strains are found in this multilayer system for samples with a $2 \mathrm{~nm}$ layer pair spacing. A larger dichroism is found in the $\mathrm{Ni} 2 \mathrm{p}$ absorption edge for a $1.8 \mathrm{~nm}$ than for a $4.4 \mathrm{~nm}$ layer pair sample. The larger dichroism is consistent with a larger magnitude of in-plane strain for the Ni layers and a larger total magnetic anisotropy energy as previously shown from magnetization curves.
\end{abstract}

\section{INTRODUCTION}

The observation of magnetic anisotropy in the metallic multilayer systems proves to be of interest for magnetic recording and magneto-optic applications. In general, the magnetic properties of metallic multilayer films are strongly dependent on the relative as well as absolute layer thicknesses. Conventional magnetometry is typically used to investigate magnetization and anisotropy of metallic films. Beyond this application, $\mathrm{x}$-ray absorption spectroscopy (XAS) can be used for measuring magnetic circular dichroism (MCD) - providing a sensitive technique for monitoring elemental specific changes in the orientation of sample magnetization. [1] For example, the remnant magnetization of $\mathrm{Fe}$ and $\mathrm{Co}$ are measured as a function of layer thickness for a series of $\mathrm{Fe}_{\mathrm{x}} \mathrm{Co}_{1-\mathrm{x}} / \mathrm{Pt}$ multilayer thin films using MCD. $[2-4]$

The microstructure of $\mathrm{Ni} / \mathrm{Au}$ multilayer samples prepared by sputter deposition have been characterized using high resolution electron microscopy, selected area diffraction and $\mathrm{x}$-ray diffraction. [5-8] A net expansion of the superlattice is measured along the growth direction for 2 $\pm 0.5 \mathrm{~nm}$ layer pair spacings. In addition, a coherent-to-incoherent (in-plane) transition at the layer interfaces was found for samples with repeat spacings greater than $2 \mathrm{~nm}$. Enhanced physical properties have been linked to this characteristic structural feature as, for example, a two-fold increase in microhardness. [9]

The magnetic properties of the $\mathrm{Ni}_{0.48} / \mathrm{Au}_{0.52}$ multilayers have been studied as a function of the Ni layer thickness using vibrating sample magnetometry and a superconducting quantum interference device. [10] It was found that the saturation magnetization $\left(\mathrm{M}_{\mathrm{S}}\right)$ of Ni decreased inversely with the $\mathrm{Ni}$ layer thickness $\left(\mathrm{d}_{\mathrm{Ni}}\right)$ while the Curie temperature $\left(\mathrm{T}_{\mathrm{c}}\right)$ followed a power law 

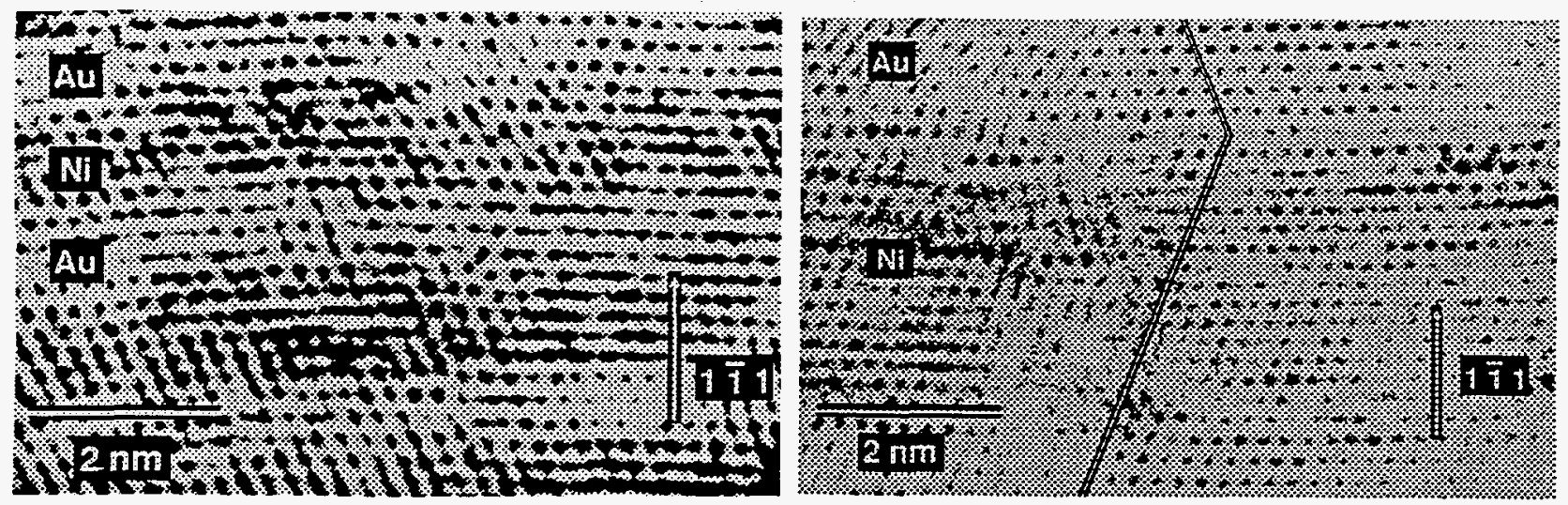

Figure 1 - High resolution lattice imaging of the (a) $1.8 \mathrm{~nm}$ layer pair (left) and (b) $4.4 \mathrm{~nm}$ layer pair (right) $\mathrm{Ni} / \mathrm{Au}$ superlattices as viewed in cross-section.[6]

behavior. Unlike these dependencies on layer thickness, an abrupt decrease in the magnetic anisotropy is found for layer pair spacings beyond the coherent-to-incoherent transition. In this study, MCD is used to further investigate the spin and orbital components of magnetic anisotropy for two $\mathrm{Ni} / \mathrm{Au}$ samples which characterize the extremes in the magnitude of superlattice strain.

\section{MULTILAYER PREPARATION \& CHARACTERIZATION}

The Ni/Au multilayer samples are prepared using sputter deposition. $[6,9,11]$ The deposition chamber is cryogenically pumped to a base pressure of $6.7 \times 10^{-6} \mathrm{~Pa}$. A circular array of planar magnetron sources is situated $20 \mathrm{~cm}$ beneath an oxygen-free copper platen. The purity of the target materials is $0.99995 \mathrm{Ni}$ and $>0.9994 \mathrm{Au}$. The magnetron sources are operated in the dc mode using an argon working gas pressure of $0.67 \mathrm{~Pa}$ at a flow rate of $20 \mathrm{cc} \mathrm{min}^{-1}$. The Si(111) substrates are sequentially rotated over each source and remain at a temperature between 293 and $306 \mathrm{~K}$ during the deposition. The sputter deposition rates of 0.10 to $1.0 \mathrm{~nm} \mathrm{sec}^{-1}$ are monitored using calibrated quartz crystals. The layer pair thickness $\left(\mathrm{d}_{\mathrm{Ni} / \mathrm{Au}}\right)$ and number of layer pairs $(\mathrm{N})$ are indicated in Table I. X-ray diffraction was used to verify the layer pair thickness. [5-8]

Structural studies of the Ni/Au multilayers have been performed using transmission electron microscopy. The films are found to be dense columnar deposits with a (111) textured growth and random in-plane orientation. [6,11] High resolution imaging is used to reveal the multilayer lattice structure. Lattice images in cross-section are recorded at the Scherzer defocus condition using a $400 \mathrm{keV}$ electron beam. The $\mathrm{Ni} / \mathrm{Au}$ multilayer samples are strained layered superlattices (Figs. 1a,b).[6] Defects in the superlattice are characterized by dislocations in the Ni layers along [-111]. The lattice misfit between the $\mathrm{Au}$ and $\mathrm{Ni}$ layers is accomodated almost entirely by dislocations within the $\mathrm{Ni}$ layers for the $4.4 \mathrm{~nm}$ repeat periodicity. For the region of the $4.4 \mathrm{~nm}$ $\mathrm{Ni} / \mathrm{Au}$ sample shown, misfit dislocations along [-111] accomodate $12.5 \%$ of the $13.6 \% \mathrm{Ni}-\mathrm{Au}$ misfit. (For the nearly incoherent superlattices, as the $4.4 \mathrm{~nm}$ layer pair sample, the Au layers 
form twin boundaries on the $\mathrm{Ni}$ layers - which also contain in-plane [1-10] dislocations.) However, for the $1.8 \mathrm{~nm}$ sample, all but a few (3.2) percent of the $\mathrm{Ni}$-Au misfit is accomodated by in-plane strain as divided between the $\mathrm{Ni}$ layer (in tension) and $\mathrm{Au}$ layer (in compression). Selected area diffraction patterns of individual columns (in cross-section) are used to compute the in-plane lattice spacings of the Ni layers, hence the coherency lattice strains $\varepsilon_{[2-20]}$, as well as the lattice strain along the growth direction $\varepsilon_{[111]}{ }^{[6]}$ Note that these strain values indicate a nonPoisson behavior indicating expansion both in-plane and along the growth direction. The strain values (listed in Table $\mathrm{I}$ ) are comparable with the present results from the dislocation-strain analysis for the lattice images of Figs. 1a,b.

Table I. Ni/Au Multilayer Parameters

\begin{tabular}{lcccccccc}
\hline \hline $\mathrm{d}_{\mathrm{Ni} / \mathrm{Au}}$ & $\mathrm{N}$ & $\varepsilon_{[2-20]}$ & $\varepsilon_{[111]}$ & $\mu_{\mathrm{SR}}{ }^{\mathrm{L}}$ & $\mu_{\mathrm{SR}} \mathrm{S}$ & $\mu_{\mathrm{SR}}$ & $\mu_{\mathrm{BR}}$ & $\mathrm{K}_{\mathrm{u}}$ \\
\hline 1.8 & 193 & 0.059 & 0.078 & 0.068 & 0.182 & 0.250 & 0.165 & 3.25 \\
4.4 & 100 & 0.014 & 0.020 & 0.033 & 0.016 & 0.049 & 0.000 & 1.70 \\
\hline
\end{tabular}

\section{MEASUREMENT \& ANALYSIS}

The $\mathrm{x}$-ray absorption spectroscopy (XAS) and magnetic circular dichroism (MCD) measurements (Figs. 2a,b) are performed on a spherical grating monochromator with the ability to generate soft $(80-1100 \mathrm{eV}) \mathrm{x}$-rays with a high degree of linear or circular polarization. $[12,13]$ The Ni/Au samples are magnetized in-situ with a pulse coil capable of generating a $3 \mathrm{kOe}$ field. To observe an MCD effect, the in-plane magnetization of the $\mathrm{Ni} / \mathrm{Au}$ films requires a grazing incidence geometry with alignment of the magnetization and $\mathrm{x}$-ray Poynting vectors. MCD in $\mathrm{x}$ ray absorption is observed as a circular polarization dependent intensity variation in the $\mathrm{L}_{\mathrm{II}}$ and $\mathrm{L}_{\mathrm{II}}$ edges for $3 \mathrm{~d}$ transition metals. The $\mathrm{x}$-ray absorption spectra are taken in a total (electron) yield mode by isolating the sample and measuring the neutralization current. The polarization dependence requires that the incident $x$-ray helicity (either parallel or anti-parallel to the direction of propagation) be aligned or anti-aligned with the sample magnetization.[1,14] MCD measures the difference in absorption between these polarized radiation conditions as the photon energy is swept through an absorption edge. The intensity difference for the $\mathrm{L}_{\text {III }}$ and $\mathrm{L}_{\text {II }}$ white lines between the parallel and anti-parallel states provides a measure of the magnetic moment as well as its orbital and spin components.

The lattice is coupled to the electron spin angular momentum through the spin-orbit interaction. Allowed transitions are determined by the dipole selection rules. In particular, we probe the $2 p$ and $3 d$ transitions. The relative strengths of the $L_{I I I}$ and $L_{I I}$ absorption edges 

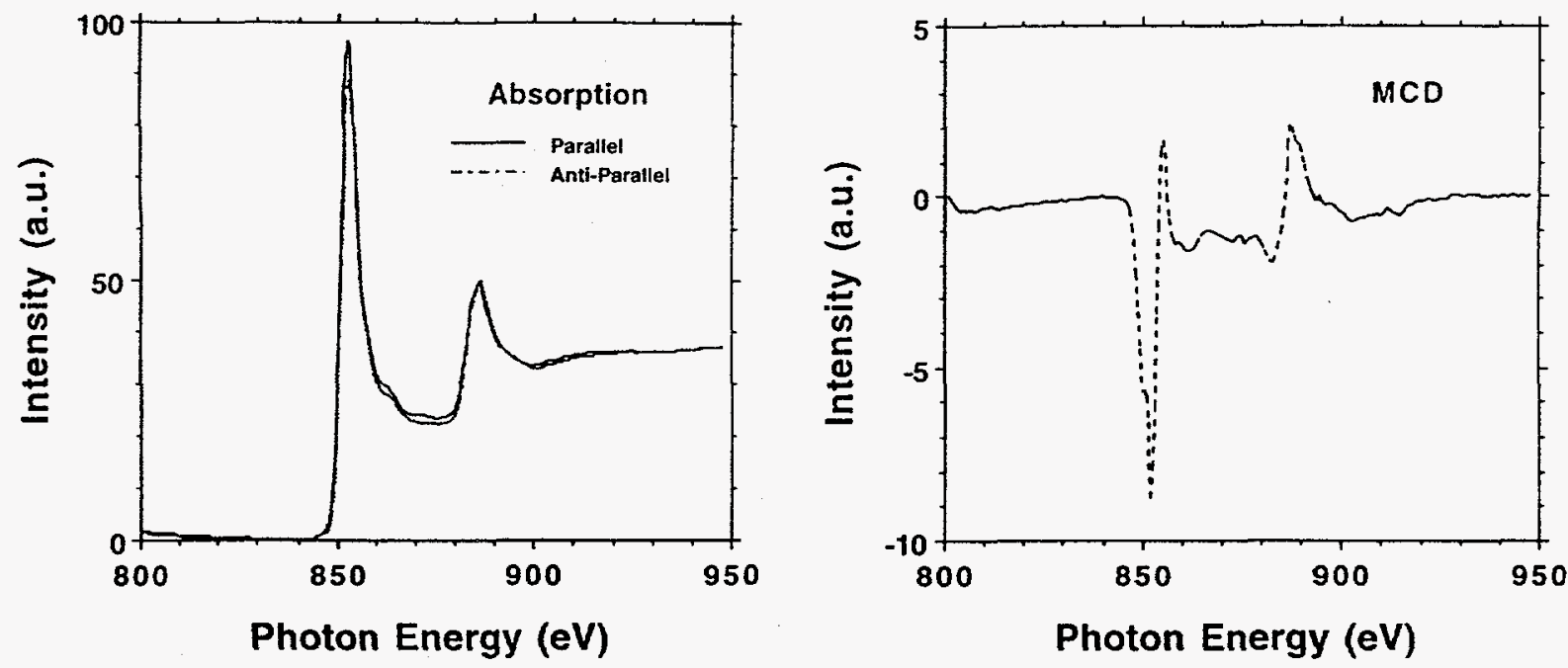

Figure 2 - The measured intensity as a function of photon energy for the (a) XAS (left) and (b) MCD (right) curves of the $1.8 \mathrm{~nm} \mathrm{Ni} / \mathrm{Au}$ superlattice. The MCD curve represents the difference divided by the sum of the XAS curves.

contain information about the spin-dependent density of states near the Fermi level and the spinorbit splitting in the d-bands (Fig. 3). Therefore, element and shell specific information is available about the spin and orbital contributions to the magnetic moments of the material.[1,15-18] Application of the sum-rule (SR) analysis yields values for the spin $\left(\mu_{S R} S\right)$ and orbital $\left(\mu_{S R}{ }^{L}\right)$ components of the total moment $\left(\mu_{S R}=\mu_{S R} S+\mu_{S R}{ }^{L}\right)$. The branching-ratio (BR) analysis yields a value for the spin moment $\left(\mu_{\mathrm{BR}}\right)$ with the apriori assumption of a small orbital moment. For $3 \mathrm{~d}$ elements, the $\mu_{\mathrm{BR}}$ is computed with the following relationships. ${ }^{[19]}$

$$
\begin{gathered}
\mu_{\mathrm{BR}}=\text { constant } \cdot\left(\mathrm{BR}^{+}-\mathrm{BR}^{-}\right) \cdot\left(\mathrm{BR}^{+}+\mathrm{BR}^{-}\right)^{-1} \\
\mathrm{BR}^{+}=\left(\mathrm{A}^{+}\right) \cdot\left(\mathrm{A}^{+}+\mathrm{B}^{+}\right)^{-1} \\
\mathrm{BR}^{-}=\left(\mathrm{A}^{-}\right) \cdot\left(\mathrm{A}^{-}+\mathrm{B}^{-}\right)^{-1}
\end{gathered}
$$

where $\mathrm{A}^{+,-}$is the integrated intensity of the $\mathrm{L}$ III peak above the background intensity and $\mathrm{B}^{+,-}$is the integrated intensity of the $\mathrm{L}_{\mathrm{II}}$ peak above the background intensity for the parallel $(+)$ and antiparallel (-) helicity and magnetization conditions, respectively (Fig. 4). For the computation of $\mu_{\mathrm{SR}}$, the following equations apply. ${ }^{[19]}$

$$
\begin{aligned}
& \mu_{\mathrm{SR}} \mathrm{S} \cong\left\{\text { constant } \cdot\left[\left(\mathrm{A}^{+} / \mathrm{C}^{+}\right)-\left(\mathrm{A}^{-} / \mathrm{C}^{-}\right)\right] \cdot(\mathrm{SUM})^{-1}\right\}-3 \cdot \mu_{\mathrm{SR}^{2}}{ }^{\mathrm{L}} \\
& \mu_{S^{2}}{ }^{L}=\text { constant } \cdot\left[\left(\mathrm{A}^{+} / \mathrm{C}^{+}\right)-\left(\mathrm{A}^{-} / \mathrm{C}^{-}\right)+\left(\mathrm{B}^{+} / \mathrm{C}^{+}\right)-\left(\mathrm{B}^{-} / \mathrm{C}^{-}\right)\right] \cdot(\mathrm{SUM})^{-1} \\
& \text { SUM }=\left[\left(\mathrm{A}^{+} / \mathrm{C}^{+}\right)+\left(\mathrm{A}^{-} / \mathrm{C}^{-}\right)+\left(\mathrm{B}^{+} / \mathrm{C}^{+}\right)+\left(\mathrm{B}^{-} / \mathrm{C}^{-}\right)\right]
\end{aligned}
$$

where $\mathrm{C}^{+,-}$is the height of the background curves above the baseline intensity. These analysis procedures applied to the XAS and MCD spectra (Figs. 2a,b) produce values for the magnetic 


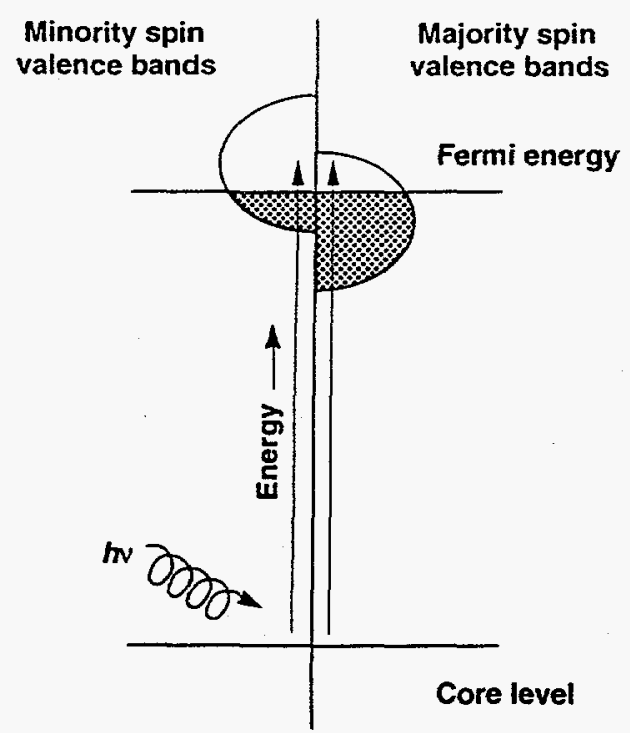

Figure 3 - A schematic (above) of the absorption of a photon and transition of an electron into an exchange split valence band density of states.

Figure 4 - A schematic (right) of $x$-ray absorption spectra with white line peaks at the $\mathrm{L}_{\mathrm{III}}$ and $\mathrm{L}_{\mathrm{II}}$ edges for the case of ferromagnetic alignment.

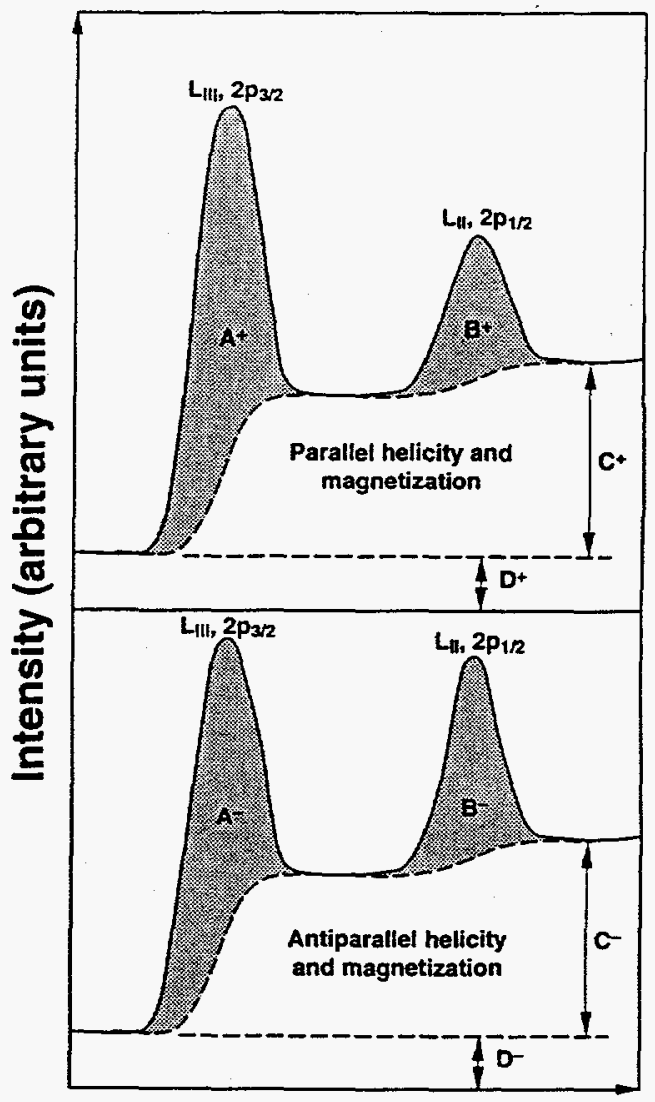

Photon energy

moments listed in Table I (in units of $\mu_{\mathrm{B}} / \mathrm{Ni}$ atom). The analyses may be complicated, however, by the polycrystalline surface. If the sample is not of a single domain, then MCD will average the domains yielding a moment that reflects the average projection of magnetization along the photon propagation direction.

\section{DISCUSSION \& SUMMARY}

The total anisotropy energy $K_{u}$ represents the difference in energy density between the parallel and perpendicular magnetized states. It is equivalent to the difference in area under the magnetization (versus applied field) curves. The total anisotropy energy can be expressed as

$$
K_{\mathrm{u}}=-\left\{2 \pi \cdot \mathrm{M}_{\mathrm{s}}^{2}+\mathrm{K}_{\mathrm{v}}+2 \cdot \mathrm{K}_{\mathrm{s}} \cdot \mathrm{d}_{\mathrm{Ni}^{-1}}\right\}
$$

where $K_{v}$ and $K_{s}$ are the volume and surface anisotropy constants, respectively. [10] The preferred in-plane magnetization for these $\mathrm{Ni} / \mathrm{Au}$ multilayers means that $\mathrm{K}_{\mathrm{u}}$ is always negative. Representative values of $K_{u}\left(10^{6} \mathrm{erg} \mathrm{cc}^{-1}\right)$ for the samples examined with XAS for MCD are listed in Table I. Whereas the coherent-to-incoherent transition for increasing layer pair spacing was observed not to have any noticeable effect on either $M_{s}$ or $T_{c}$, a lattice strain effect is apparent on $\mathrm{K}_{\mathrm{u}}$. 
The magnetic behavior of lattice strained and unstrained $\mathrm{Ni} / \mathrm{Au}$ multilayers have been probed using MCD. The MCD results are consistent with the magnetic anisotropy measurement of these films as previously determined through magnetization curves. [5] A large decrease in the spin component, from 0.182 to $0.016 \mu_{\mathrm{B}} / \mathrm{Ni}$ atom, is found with the sum-rule analysis as the in-plane strain of the Ni layer decreases from $5.9 \%$ to $1.4 \%$ (with an increase in the Ni layer thickness from 0.91 to $2.1 \mathrm{~nm}$ ). Results for the branching ratio analysis yield nearly equivalent results as for the spin component. The magnitude of decrease (by a factor of 2 ) in the total anisotropy energy $K_{u}$ is equal to the decrease in the orbital component, from 0.068 to $0.033 \mu_{B} / \mathrm{Ni}$ atom, which therefore serves as an indicator of elastic strain effects on crystalline lattice. These results confirm a magneto-elastic effect in the magnetization behavior of the $\mathrm{Ni} / \mathrm{Au}$ multilayer system.

\section{ACKNOWLEDGMENTS}

This work was performed under the auspices of the United States Department of Energy by Lawrence Livermore National Laboratory under contract W-7405-Eng-48.

\section{REFERENCES}

1. J.G. Tobin, G.D. Waddill and D.P. Pappas, Phys. Rev. Lett. 68, 3642 (1992).

2. A. Jankowski, G.D. Waddill and J. Tobin, Mat. Res. Soc. Symp. Proc. 313, 227 (1993).

3. A.F. Jankowski, G.D. Waddill and J.G. Tobin, J. Vac. Sci. Technol. A 12, 2215 (1994).

4. J. Tobin, A. Jankowski, G. Waddill and P. Sterne, Mat. Res. Soc. Symp. Proc. 343 (1994).

5. A.F. Jankowski, Superlatt. Microstruc. 6, 427 (1989).

6. A.F. Jankowski, J. Appl. Phys. 71, 1782 (1992).

7. J. Chaudhuri, S. Shah, V. Gondhalekar and A. Jankowski, J. Appl. Phys. 71, 3816 (1992).

8. J. Chaudhuri, S. Alyan and A. Jankowski, Thin Solid Films 219, 63 (1992).

9. A.F. Jankowski, J. Magn. Magn. Mat. 126, 185 (1993).

10. J.R. Childress, C.L. Chien and A.F. Jankowski, Phys. Rev. B 45, 2855 (1992).

11. M.A. Wall and A.F. Jankowski, Thin Solid Films 181, 313 (1989).

12. K.G. Tirsell and V. Karpenko, Nucl. Instrum. Meth. A 291, 511 (1990).

13. L.J. Terminello, G.D. Waddill and J.G. Tobin, Nucl. Instrum. Meth. A 319, 271 (1992).

14. J.L. Erskine and E.A. Stern, Phys. Rev. B 12, 5016 (1975).

15. B.T. Thole and G. van der Laan, Phys. Rev. A 38, 1943 (1988).

16. B.T. Thole and G. van der Laan, Phys. Rev. B 42, 6670 (1990).

17. B.T. Thole, P. Carra, F. Sette and G. vander Laan, Phys. Rev. Lett. 68, 1943 (1992).

18. P. Carra, B.T. Thole, M. Altarelli and X. Wang, Phys. Rev. Lett. 70, 694 (1993).

19. J.G. Tobin, G.D. Waddill, A.F. Jankowski, P.A. Sterne and D.P. Pappas, (to be submitted). 